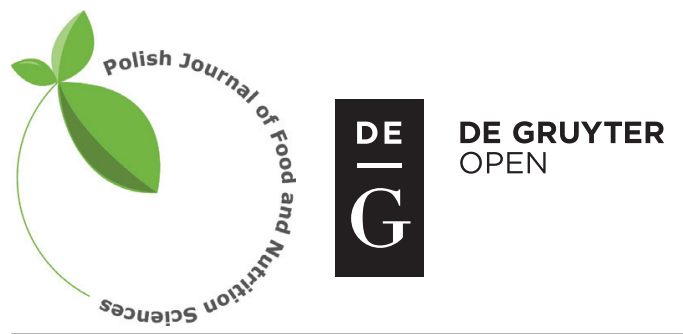

Pol. J. Food Nutr. Sci., 2018, Vol. 68, No. 2, pp. 115-123

DOI: $10.1515 /$ pjfns-2017-0014 http://journal.pan.olsztyn.pl

Original research article

Section: Food Quality and Functionality

\title{
Rapid and Specific Detection of Escherichia coli 0157:H7 in Ground Beef Using Immunomagnetic Separation Combined with Loop-Mediated Isothermal Amplification
}

\author{
Yu Qin , Santhosh Puthiyakunnon", Yiduo Zhang, Xianbo Wu, Swapna Boddu, Binde Luo, Hongying Fan*
}

\author{
Guangdong Provincial Key Laboratory of Tropical Disease Research, \\ School of Public Health, Southern Medical University, Guangzhou, 510515, China
}

Key words: immunomagnetic separation, LAMP, Escherichia coli, EHEC O157:H7, rfbE gene, ground beef

Escherichia coli $\mathrm{O} 157: \mathrm{H} 7$ is well known for many foodborne outbreaks that lead to fatal infections in human being worldwide. The objective of this study was to develop a rapid and sensitive method for detection of EHEC O157:H7 from ground beef using a method that combined immunomagnetic separation (IMS) with loop-mediated isothermal amplification (LAMP). The EHEC O157:H7 cells were separated with Dynabeads coated with antiEHEC O157:H7 after a short enrichment for $4 \mathrm{~h}$. Then, EHEC O157:H7 was identified by LAMP assay for amplifying and detecting the $r f b E$ gene, which is highly conserved in all EHEC O157:H7 strains and exhibits strain-specific gene expression. The LAMP method results analyzed with real time turbidity measurements showed a high specificity and sensitivity, with a positive detection rate of amplification of EHEC O157:H7 DNA diluted to a minimum equivalent concentration of $1.8 \times 10^{1} \mathrm{CFU} / \mathrm{mL}$, which was 10 times more sensitive than the conventional PCR assay. The IMS followed with LAMP could capture and detect a bacterial concentration as low as $3 \times 10^{1} \mathrm{CFU} / \mathrm{mL}$ from the meat samples, which was close to the sensitivity of LAMP assay with pure culture. IMS combined with realistic LAMP method is a simple, rapid, highly specific gene amplification technology that is suitable for implementing as a screening assay in basic laboratory and field test for detecting food contamination.

\section{INTRODUCTION}

EHEC O157:H7 is an Enterohemorrhagic serotype of the bacterium Escherichia coli, which can cause fatal infection that may lead to hemorrhagic colitis (HC), hemolytic uremic syndrome (HUS), thrombotic thrombocytopenic purpura (TTP), and kidney failure [Karsh et al., 2005]. EHEC infection diarrhea is still one of the major public health problems world-wide and some previous studies have investigated the EHEC O157:H7 human infection causing mortality rate ranging between 0 to $10 \%$ [Mckee \& O'Brien, 1995; Gianviti et al., 1994; Bell et al., 1997]. After the first US outbreak of EHEC O157:H7 infection in 1982, many outbreaks and sporadic cases caused by the bacteria have been reported. A recent, multistate outbreak of Shiga toxin-producing EHEC O157:H7 infections that occurred in the US from April to June 2014 and was linked to ground beef, has caused an increased alarm on food safety. During 1999-2000, the Jiangsu, Anhui and Henan Provinces in China faced a massive outbreak of EHEC O157:H7 which caused 177 deaths due to hemolytic uremic syndrome [Xiong et al., 2012].

Transmission is via the fecal-oral route, typically through consumption of contaminated food like raw leaf green veg-

\footnotetext{
* Corresponding Author: Tel.: +8620 62789123;

E-mail: biofhy@126.com (Dr. Fan Hongying, M.D., Ph.D.)

These authors contributed equally.
}

etables and undercooked meat [Onoue et al., 1999]. The minimum infectious dose (MID) of EHEC O157:H7 is estimated to be around 10 to $100 \mathrm{CFU}$ compared to more than one million CFU for other pathogenic strains of $E$. coli, mainly due to their increased virulence and toxicity [Greig et al., 2010]. EHEC O157:H7 can naturally be found in the intestinal contents of some cattle [Jeon et al., 2013] and due to the lack of receptors, they mainly act as asymptomatic carriers of the bacterium serving as an important source of infection to human [Pruimboom-Brees et al., 2000]. Cattle is regarded as 'super-shedders' of these bacteria as they colonize the recto-anal junction and excrete more than $10^{3}$ to $10^{4} \mathrm{CFU}$ per gram of feces and may account for more than $90 \%$ of all E. coli O157:H7 excreted [Chase-Topping et al., 2008]. As E. coli inhabits the intestine as a normal commensal, identification of this serotype with serological as well as molecular tests at a genetic level is mandatory to elucidate its extent of carriage rate and source of infection to humans.

Currently, EHEC O157:H7 diagnosis relies mainly on traditional and immunomagnetic methods of isolation and culture of bacteria followed by biochemical identification, serotyping, and PCR. As most of the conventional methods require at least $2-3$ days for getting the result and another one week for confirmation, PCR-based methods that target some specific virulence factor genes such as $s t x l$, st 2 , eaeA, fliC, Z3276 and hlyA, are used for detection of E.coli O157:H7 strains [Aydin et al., 2014; Ravan et al., 2016]. Some previously published reports from our lab and elsewhere 
have indicated that gene sequences encoding $r f b E$ are highly conserved among EHEC O157:H7 [Bilge et al., 1996; Desmarchelier et al., 1998; Jiang et al., 2012]. Hence in this study, we targeted the $r f b E$ gene expression for specific detection of EHEC O157:H7 by loop-mediated isothermal amplification (LAMP) after immunomagnetic enrichment of the food samples.

A large number of field applications showed that the $\mathrm{O} 157$ immunomagnetic method greatly improved the isolation rate of bacteria [Buesa et al., 2002; Wolf et al., 2007]. The clinical samples for diagnosis are initially treated with a specific antibody-coated beads, and the target bacteria after reaction with their specific antibody are separated from other bacteria by immunomagnetic separation (IMS) [Bapanpally et al., 2014; Taguchi et al., 2007]. Loop-mediated isothermal amplification (LAMP) is a sensitive, specific, convenient and fast nucleic acid amplification technology, which obviates the need for expensive thermal cyclers used in conventional PCR [Saito et al., 2005]. The LAMP was designed with four specific primers for the six regions of the unique target gene using strand displacement DNA polymerase activity in addition to a nucleic acid amplification activity at a constant temperature of $60-65^{\circ} \mathrm{C}$ [Hara-Kudo et al., 2008]. A final amplification for LAMP using an additional pair of "loop primers" yields a higher amount of DNA and scope for naked eye screening of the amplification based on visible turbidity due to magnesium pyrophosphate precipitation [Mori et al., 2001; Nagamine et al., 2002]. Since its development in 2000 [Notomi et al., 2000], the LAMP technology has been widely used in the diagnosis of clinical disease including bacterial or viral epidemic qualitative and quantitative testing and in other various applications [Hara-Kudo et al., 2007; Kou et al., 2014; Saito et al., 2005; Wang et al., 2012; Wang et al., 2015].

In this study, we explored the use of IMS method and LAMP technology to establish a rapid and sensitive method for the detection of EHEC 0157:H7 from ground beef matrices. Our research findings indicate the future prospects for development of a more reliable and sensitive method for isolation and identification of EHEC O157:H7 from important sources of infection to humans, which will be a promising requisite in low-resource or field settings, where a conventional DNA or RNA extraction prior to diagnostic testing may be impractical.

\section{MATERIALS AND METHODS}

\section{Bacterial strains}

In this study, 19 bacterial strains including 5 EHEC O157:H7 and 14 other bacterial strains were tested using the LAMP assay to show specificity. The EHEC O157:H7 standard strain (ATCC 43889) and four wild stains of EHEC O157:H7 were obtained from the American Type Culture Collection (Rockville, MD, USA) and Guangdong Provincial Institute of Microbiology (GIM- 4 isolated strains). The non O:157 E. coli (ATCC 25922, CMCC 44102 and SMU (Southern Medical University) -2 strains) and other bacterial strains including Staphylococcus aureus (ATCC 25923 and ATCC 26003), Shigella spp. (ATCC 12022 and CMCC 51105), Salmonella spp. (ATCC 14028 and ATCC 10376), Vibrio para- haemolyticus (ATCC 17802, GIM-2 strains), and Klebsiella pneumoniae (ATCC 700603) were procured from the Guangdong Institute of Microbiology (GIM), China Microbiological Culture Collection (CMCC) and also from the stock cultures of the Department of Microbiology of Southern Medical University (SMU), Guangzhou, China. All bacterial strains were cultured in Luria-Bertani broth (Huankai, China) at $37^{\circ} \mathrm{C}$ overnight. DNA was extracted using a DNA Gel extraction kit (Sangon Ltd., Shanghai, China). The DNA samples were stored at $-20^{\circ} \mathrm{C}$ for later use. DNA template was prepared using TaKaRa universal genomic DNA extraction kit according to instructions.

\section{LAMP primers and analysis of LAMP products}

The EHEC O157:H7 LAMP assay required three sets of primers (outer and inner), which were previously designed in our lab by analyzing a conserved region of the $r f b E$ gene sequence published in Gene bank (GenBank: S83460.1) [Jiang et al., 2012]. The primer design software, Primer Explorer 5.0 was used to design the specific LAMP primers, including two outer primers F3 and B3, two inner primers FIP, BIP and two loop primers LB, LF. Primers were synthesized by Shanghai Sangon Biological Engineering Technology Services Limited. Primer sequence and the gene sequence are schematically shown in Figure 1 and Table 1.

The LAMP reaction was performed as described previously [Hill et al., 2008; Yamazaki et al., 2008]. Each reaction mixture (total volume of $25 \mu \mathrm{L}$ ) contained $10 \times$ Bst ThermoPol buffer $2.5 \mu \mathrm{L}, \mathrm{MgCl}_{2}$ (25 mmol/L) $3 \mu \mathrm{L}$, dNTP's (each $2.5 \mathrm{mmol} / \mathrm{L}$ ) $3 \mu \mathrm{L}$, betaine $(5 \mathrm{~mol} / \mathrm{L}) 2 \mu \mathrm{L}$, inner primers $(40 \mu \mathrm{mol} / \mathrm{L})$ of each $1 \mu \mathrm{L}$, outer primers $(10 \mu \mathrm{mol} / \mathrm{L})$ of each $1 \mu \mathrm{L}$, loop primer $(10 \mu \mathrm{mol} / \mathrm{L})$ of each $1 \mu \mathrm{L}$, Bst DNA polymerase (New England Biolabs, Inc., Ipswich, MA) large fragment $1 \mu \mathrm{L}$ (8units), DNA template $2 \mu \mathrm{L}$, and $\mathrm{ddH}_{2} \mathrm{O} \times 5.5 \mu \mathrm{L}$. After mixing, the LAMP reaction mix was subjected to analysis using the LA-500 real time turbidity detection system (Eiken Chemical Co. Ltd., Japan).

\section{Polymerase Chain Reaction (PCR)}

The PCR assay for $r f b E$ gene was performed using the LAMP outer primers (F3 and B3) in a total reaction volume of $25 \mu \mathrm{L}$ to yield a product of $206 \mathrm{bp}$. The reaction mix contains $2.5 \mu \mathrm{L} 10 \times$ PCR buffer $(100 \mathrm{mmol} / \mathrm{L}$ Tris- $\mathrm{HCl}$, $\mathrm{pH} 8.3,15 \mathrm{mmol} / \mathrm{L} \mathrm{MgCl}_{2}$, and $0.01 \%$ gelatin), $200 \mu \mathrm{mol} / \mathrm{L}$ of each deoxynucleoside triphosphate, $200 \mathrm{nmol} / \mathrm{L}$ of each primer (F3 and B3), $1 \mathrm{U}$ of Taq polymerase, and $2 \mu \mathrm{L}$ of sample DNA. A BiometraPCR cycler (Germany UNOII-Themoblockt TM) was used for amplification with reaction conditions including heat denaturation by incubation at $94^{\circ} \mathrm{C}$ for $5 \mathrm{~min}$, and then 30 cycles at $94^{\circ} \mathrm{C}$ for $40 \mathrm{~s}$, annealing at $60^{\circ} \mathrm{C}$ for $40 \mathrm{~s}$, and extension at $72^{\circ} \mathrm{C}$ for $1 \mathrm{~min}$, followed by the final extension at $72^{\circ} \mathrm{C}$ for $7 \mathrm{~min}$. PCR products $(5 \mu \mathrm{L})$ were subjected to electrophoresis in $2.5 \%$ agarose gel and visualized by ethidium bromide staining using the GL200 gel imaging system (US Eastman Kodak Company).

\section{Sensitivity and specificity of LAMP assay}

Sensitivity and specificity of LAMP assay was determined by using the EHEC 0157:H7 ATCC 43889 standard stain. 


\section{1 tcaacagtcttgtacaagtccacaaggaaagtaaagatgttttcacacttattggatgg $\mathrm{F} 3$ \\ 961 tctcaattctaactaggaccgcagaggaaagagaggaattaaggaatcacttgcagata F2 LF 1021 aactcatcgaaacaaggccagttttttaccctgtccacacgatgccaatgtactcggaaa B1c LB 1081 aatatcaaaagcaccctatagctgaggatcttggttggcgtggaattaatttacctagtt B2 B3}

FIGURE 1. Names and locations of target sequences used as primers for loop-mediated isothermal amplification (LAMP). The sequence of the EHEC O157:H7 rfbE gene, together with the primer name and the location of each target sequence (in boldface) are shown. Arrows indicate the position of the target sequences in EHEC O157:H7 rfbE gene.

A 10 fold serial dilution of the strain was made up to a final volume of $1 \mathrm{~mL}$ to obtain a final concentration ranging from $10^{6}$ to $10^{1}$ colony-forming units $(\mathrm{CFU}) / \mathrm{mL}$. DNA templates were made from each dilutions using a DNA extraction kit as mentioned above, and $2 \mathrm{~mL}$ aliquots from each dilution were subjected to LAMP and PCR amplifications. Sensitivity tests were repeated three times, and the lower limits of detection $(\mathrm{CFU} / \mathrm{mL})$ were reported. A total of 19 bacterial strains, as mentioned previously, were used to determine LAMP specificity.

\section{Meat sample preparation for IMS}

To establish immunomagnetic separation after enrichment and detection by LAMP from the ground beef source, we purchased the beef meat from Guangzhou, the farmers' markets and supermarkets. Prior to the inoculation of EHEC O157:H7, these meat samples were examined for natural contamination with EHEC O157:H7 and confirmed negative by the IMS-plating method described below in combination with enrichment in nutrient broth. Before spiking the meat samples, the standard inoculum of EHEC O157:H7 (ATCC 43889) was prepared by inoculating the strain into LB liquid medium and incubating overnight at $37^{\circ} \mathrm{C}$ with constant shaking. Meat samples were inoculated with EHEC O157:H7 at a final concentration of $1.2 \times 10^{3} \mathrm{CFU} / 500 \mathrm{~g}$, after reconstituting with sterile PBS. For negative control, equal volume of un-inoculated, sterile PBS was spiked into the meat sample.

\section{Immunomagnetic separation (IMS) and culture onto SMAC}

IMS was performed using Dynabeads anti-EHEC O157 (Dynal, Oslo, Norway) on a $1 \mathrm{~mL}$ enrichment culture as described previously [Wright et al., 1994]. Meat sample (25 g) in $225 \mathrm{~mL}$ of nutrient broth was homogenized by a Stomacher (Stomacher 400, Seward Medical, London, UK) for $1 \mathrm{~min}$, and enriched for $4 \mathrm{~h}$ before subjecting to IMS. For IMS, $1 \mathrm{~mL}$ of the nutrient broth culture was mixed with $20 \mu \mathrm{L}$ of Dynabeads anti-EHEC 0157:H7 in an Eppendorf tube and incubated at room temperature for $20 \mathrm{~min}$. The beads were separated using a magnetic particle concentrator (MPC-M ${ }^{\mathrm{TM}}$ Dynal), washed with $1 \mathrm{~mL}$ of PBS containing $0.05 \%$ Tween 20 , and re-suspended in $300 \mu \mathrm{L}$ of PBS-Tween 20 for a final wash. Beads were re-suspended in $25 \mu \mathrm{L}$ of nutrient broth, plated onto an agar plate and colony counts were made after 18 $24 \mathrm{~h}$ incubation at $37^{\circ} \mathrm{C}$. Sorbitol non-fermenting colonies
TABLE 1. Sequences of Loop mediated isothermal amplification primers.

\begin{tabular}{lc}
\hline Primer & Sequence $\left(5^{\prime}-3^{\prime}\right)$ \\
\hline F3 & ggaaagtaaagatgttttcacac \\
B3 & aattaattccacgccaacc \\
FIP(F1c+F2) & gagtttatctgcaaggtgattcctt-gatggtctcaattctaactagga \\
BIP(B1c+B2) & tcgaaacaaggccagtttttacc-atcctcagctatagggtgc \\
LF & tcctctctttcctctgcgg \\
LB & ctgtccacacgatgccaatg \\
\hline
\end{tabular}

were tested for agglutination with a latex test kit (DR120M, Oxoid) for detecting EHEC O157:H7 and further confirmed by biochemical tests (Crystal ID, Becton Dickinson, Oxford, UK) and also by serotyping with EHEC O157:H7 rabbit antiserum (Mast Diagnostics, Liverpool, UK). IMS was repeated for LAMP assay.

\section{RESULTS}

\section{LAMP detection method}

LAMP amplification was performed for two standard strains of EHEC O157:H7 and a non-O157:H7 as a negative control. The corresponding curves of genomic DNA detection by real time turbidity for EHEC O157:H7 EDL 933 and ATCC 43889 are shown in Figure 2A. Gel electrophoresis of specific amplification of EHEC O157:H7 rfbE gene using two primers F3 and B3 by conventional PCR showed the amplification product corresponding to 206bp in EHEC O157:H7 reference strains (Figure 2B), and not in the negative control, which is also consistent with the result obtained with LAMP detection method.

\section{Specificity of the LAMP assay}

LAMP was tested for its specificity using 5 EHEC O157:H7 strains and 14 other bacterial strain DNA samples. Only the target EHEC O157:H7 DNA was amplified. No LAMP products were detected in the reactions performed with DNA from non-O157:H7 or any other strains (Figure 3A). Both LAMP and PCR specifically amplified $r f b E$ DNA from EHEC O157:H7, whereas in the negative-control, DNA was not amplified (Figure 3B). No false positive amplification was observed in LAMP method, indicating high specificity of the established LAMP assays.

\section{Sensitivity of the LAMP assay}

The LAMP method result showed a high sensitivity, with a positive detection rate of amplification of the DNA of EHEC O157:H7 diluted to a minimum equivalent concentration of $1.8 \times 10^{1} \mathrm{CFU} / \mathrm{mL}$ (Figure 4A). On PCR amplification, the positive result was shown with the minimum equivalent concentration of $1.8 \times 10^{2} \mathrm{CFU} / \mathrm{mL}$ EHEC O157:H7 (Figure 4B). The un-inoculated broth serving as a negative control did not show any amplification in both LAMP and PCR method. Our result shows that LAMP assay was 10 times more sensitive than the conventional PCR assay. 
A

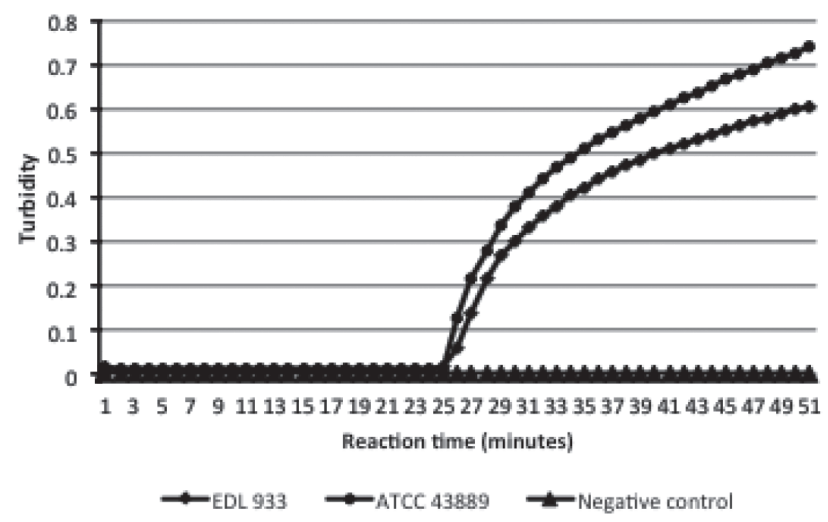

B

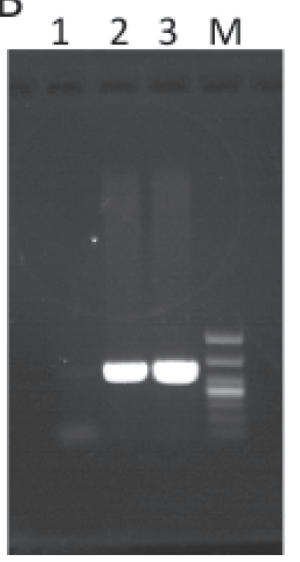

FIGURE 2. Detection of EHEC O157: H7 standard strain by LAMP assay and PCR method. (A) LAMP assay detection analyzed by real time turbidity measurement. The corresponding curves of genomic DNA represents EHEC O157:H7 EDL 933 and ATCC 43889 detections by LAMP amplification. (B) EHEC O157:H7 rfbE gene amplification (206bp) by PCR (Lanes 1: Negative control) 2: EHEC O157:H7 ATCC 43889; 3: EHEC O157:H7 EDL 933, M: 100bp marker).

\section{Comparison of sensitivity of IMS-LAMP assay and PCR amplification with conventional SMAC agar culture method}

We have established immunomagnetic separation after enrichment and detection of EHEC O157:H7 with LAMP assay from the ground beef source in order to compare the detection efficacy of conventional culture method with the IMSLAMP amplification method. The inoculation level of EHEC O157:H7 was $4.6 \times 10^{0}$ to $4.6 \times 10^{7} \mathrm{CFU} / \mathrm{mL}$ for 25 grams of ground beef before the samples were subjected to immunomagnetic separation. The EHEC were detected with different methods including culture onto SMAC agar and colony counts, IMS-LAMP method and conventional PCR amplification methods. On comparison of sensitivity of various methods (Table 2), we found that IMS-LAMP method after enrichment for 4 hours could detect the pathogen in the samples inoculated with $4.6 \times 10^{1} \mathrm{CFU} / \mathrm{mL}$. The turbidity method by naked eye examination could detect from the lowest level

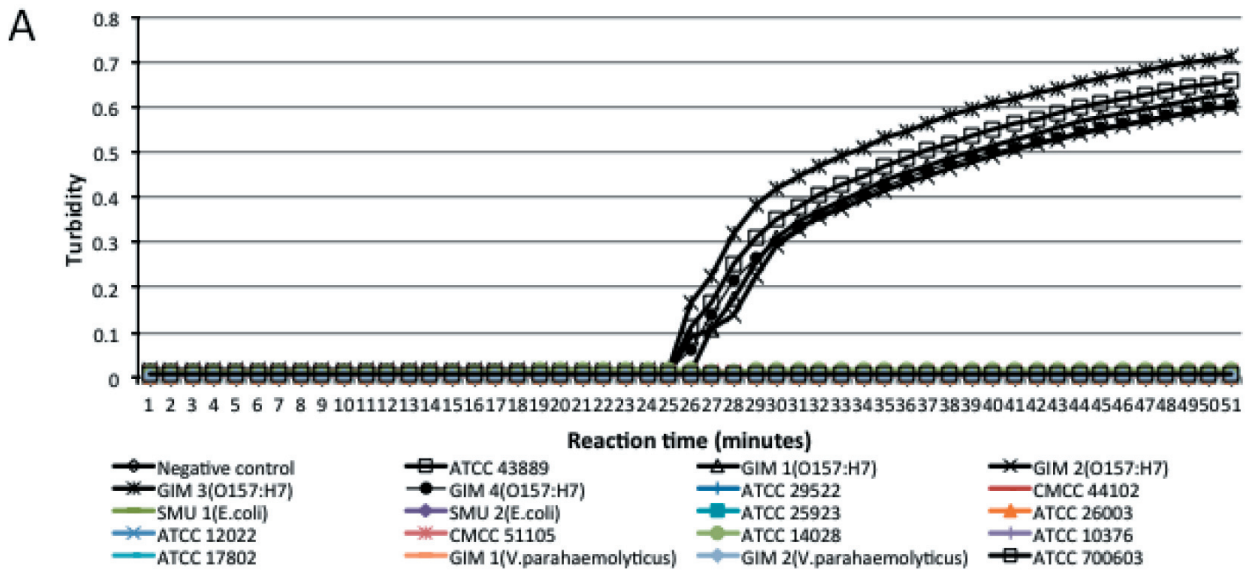

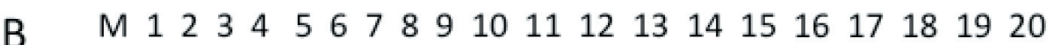

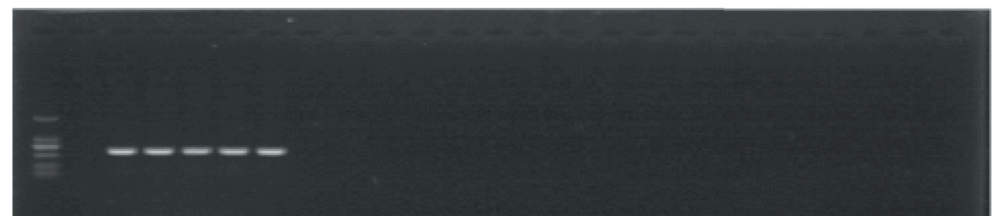

FIGURE 3. Specificity of LAMP assay and PCR method for detection of EHEC O157:H7. (A) Specificity of LAMP assay detection analyzed by real time turbidity measurement. The corresponding curves of genomic DNA of 5 strains of EHEC O 157:H7 (ATCC 43899 and GIM strains 1 to 4) were marked in the figure. Non EHEC O157:H7 strains and other bacterial strains did not give any positive curves showed 100\% specificity of LAMP assay. (B) Electrophoretic analysis of EHEC O157:H7 polymerase chain reaction (PCR)-amplified products. Both LAMP assay and PCR detected only the EHEC O157:H7 and no other strains. (M: 100bp marker; Lane 1: Negative control; 2: ATCC 43889; 3: GIM1 (O157:H7); 4: GIM2 (O157:H7); 5: GIM3 (O157:H7); 6: GIM3 (O157:H7); Lane 7 to 20: 14 other non-O157 E.coli strains and other bacterial strains as mentioned in materials and methods. 
TABLE 2. Comparison of quantitative detection of EHEC O157:H7 by IMS-LAMP screening method with SMAC plating method.

\begin{tabular}{l|c|c|c|c}
\hline \multirow{2}{*}{$\begin{array}{l}\text { Bacterial } \\
\text { suspension } \\
(\mathrm{CFU} / \mathrm{mL})\end{array}$} & $\begin{array}{c}\text { SMAC } \\
\text { inoculation } \\
(\mathrm{CFU})\end{array}$ & \multicolumn{4}{|c}{$\begin{array}{c}\text { Immunomagnetic } \\
\text { Enrichment Screening }\end{array}$} \\
\cline { 3 - 5 } & $\begin{array}{c}\text { LAMP } \\
\text { LA-500 }\end{array}$ & $\begin{array}{c}\text { LAMP } \\
\text { precipitate }\end{array}$ & PCR \\
\hline $4.6 \times 10^{0}$ & $+(7)$ & - & - & - \\
$4.6 \times 10^{1}$ & $+(54)$ & + & - & - \\
$4.6 \times 10^{2}$ & $+(188)$ & + & + & + \\
$4.6 \times 10^{3}$ & $+($ Uncountable $)$ & + & + & + \\
$4.6 \times 10^{4}$ & + (Uncountable $)$ & + & + & + \\
$4.6 \times 10^{5}$ & + (Uncountable $)$ & + & + & + \\
$4.6 \times 10^{6}$ & + (Uncountable $)$ & + & + & + \\
$4.6 \times 10^{7}$ & + (Uncountable $)$ & + & + & + \\
\hline
\end{tabular}

of $4.6 \times 10^{2} \mathrm{CFU} / \mathrm{mL}$. The PCR showed a positive result from $4.6 \times 10^{2} \mathrm{CFU} / \mathrm{mL}$, same as the LAMP precipitate method. Therefore, the detection limit of EHEC O157:H7 by combining IMS and LAMP method followed by real time turbidity detection assay system in our study was $4.6 \times 10^{1} \mathrm{CFU} / \mathrm{mL}$.

\section{Sensitivity of IMS-LAMP method for EHEC O157:H7 detection in artificially spiked ground beef samples}

Artificial bacterial contamination of the ground beef samples was done by spiking the ground beef samples with an inoculum of EHEC O157:H7 as mentioned previously.
After enrichment for 4 hours, LAMP could detect the bacterial DNA with a detection limit as low as $3.0 \times 10^{1} \mathrm{CFU} / \mathrm{mL}$, which is close to the sensitivity of LAMP assay with pure culture (Figure 5A). The PCR amplification bands could be detected in agarose gel electrophoresis only up to a final dilution of $3.0 \times 10^{2} \mathrm{CFU} / \mathrm{mL}$ (Figure $5 \mathrm{~B}$ ). Thus, the sensitivity of IMS-LAMP assay was 10 times more than that of the PCR.

\section{Evaluation of IMS-LAMP assay and IMS-PCR method for EHEC 0157:H7 in practice}

Finally, we have performed the field application of our standardized IMS-LAMP assay by evaluating the contamination of meat with EHEC O157:H7 by procuring meat kept for sale in shops around our study area. IMS-LAMP and PCR were performed after processing the ground beef samples for immunomagnetic separation. Out of 39 samples we have processed, two samples turned out positive for contamination with EHEC 0157:H7 (Figure 6A \& 6B). We have also analyzed the results using positive and negative controls in accordance with the National Standard Method (GB/T4789.62003). The IMS-LAMP method results were consistent with the previous results [Zeng et al., 2014], and when compared with the PCR and the National Standard Method (GB/ T4789.6-2003), IMS-LAMP method was rapid and showed higher sensitivity and specificity.

\section{DISCUSSION}

EHEC O157:H7 is a major serotype of enterohemorrhagic $E$. coli, which was included by the WHO as a new foodborne patho-

A
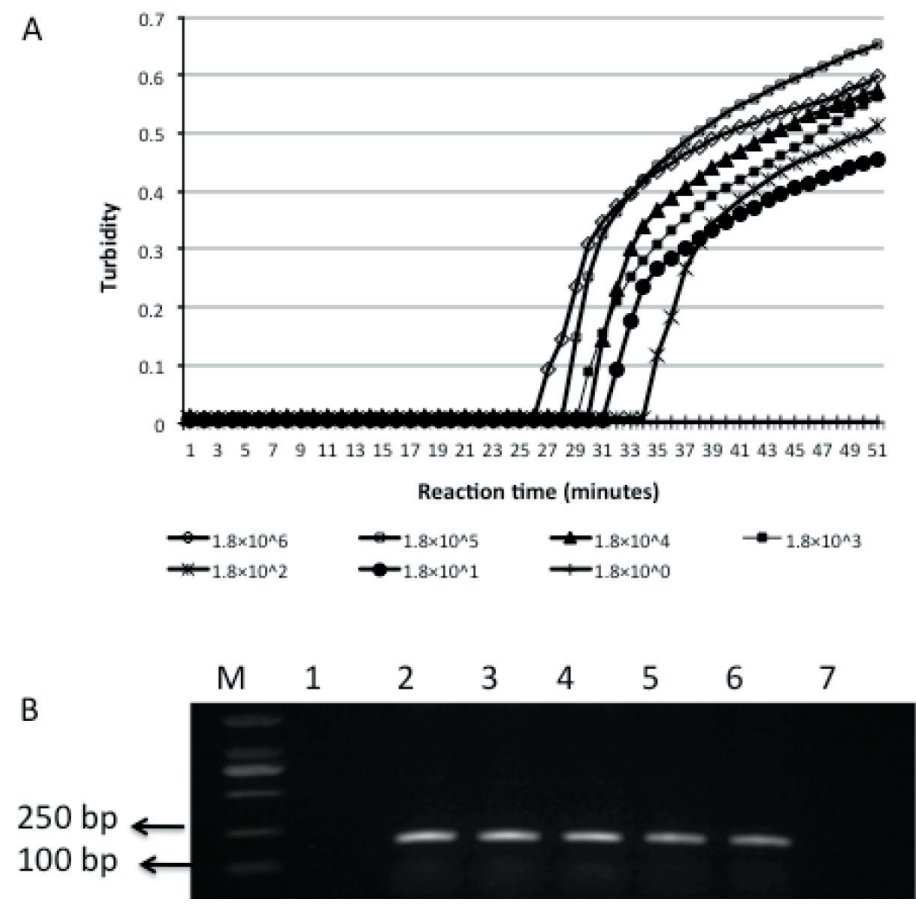

FIGURE 4. Comparative sensitivity of the LAMP assay and PCR method for detection of EHEC O157:H7. (A) Sensitivity of LAMP assay detection analyzed by real time turbidity measurement. The corresponding curves of genomic DNA represents five dilutions of EHEC O157:H7; 1: $1.8 \times 10^{6} \mathrm{CFU} / \mathrm{mL} ; 2: 1.8 \times 10^{5} \mathrm{CFU} / \mathrm{mL} ; 3: 1.8 \times 10^{4} \mathrm{CFU} / \mathrm{mL} ; 4: 1.8 \times 10^{3} \mathrm{CFU} / \mathrm{mL} ; 5: 1.8 \times 10^{2} \mathrm{CFU} / \mathrm{mL} ; 6: 1.8 \times 10^{1} \mathrm{CFU} / \mathrm{mL} ; 7: 1.8 \times 10^{\circ} \mathrm{CFU} / \mathrm{mL}$. (B) Electrophoretic analysis of EHEC O157:H7 polymerase chain reaction (PCR)-amplified products. M: 2000bp marker; 1: Negative control; 2: $1.8 \times 10^{6} \mathrm{CFU} / \mathrm{mL} ; 3: 1.8 \times 10^{5} \mathrm{CFU} / \mathrm{mL} 4: 1.8 \times 10^{4} \mathrm{CFU} / \mathrm{mL} ; 5: 1.8 \times 10^{3} \mathrm{CFU} / \mathrm{mL} ; 6: 1.8 \times 10^{2} \mathrm{CFU} / \mathrm{mL} ; 7: 1.8 \times 10^{1} \mathrm{CFU} / \mathrm{mL}$. The sensitivity of LAMP assay was 10 times more than the conventional PCR. 
A

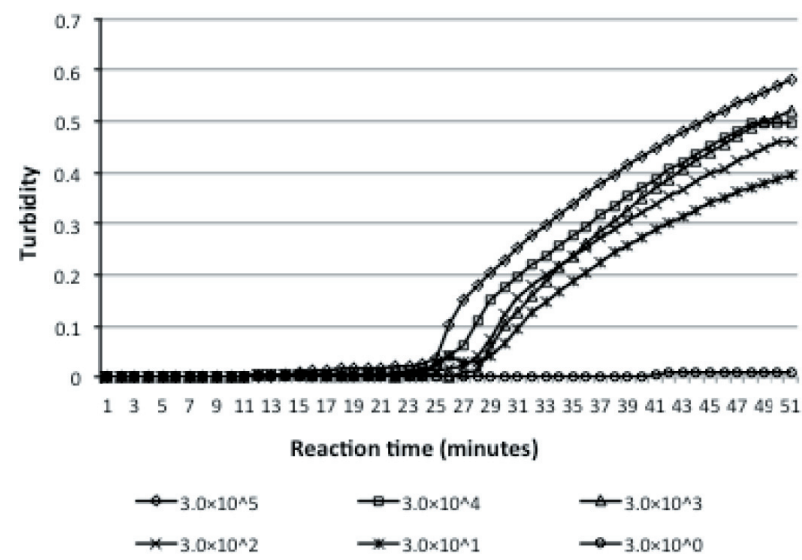

B

M 123456

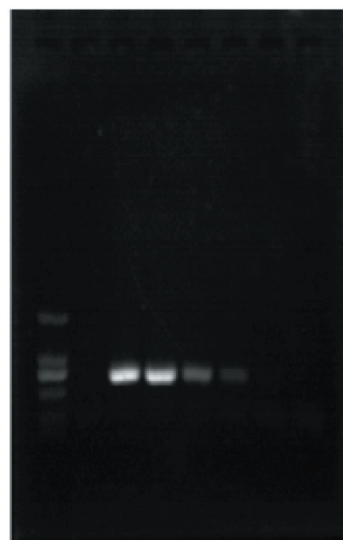

FIGURE 5. Comparison of sensitivity of IMS-LAMP assay with PCR in detection of EHEC O157:H7 in artificially contaminated ground beef. (A) Sensitivity of IMS-LAMP assay detection analyzed by real time turbidity measurement. The corresponding curves of genomic DNA represents five dilutions of EHEC O 157:H7; $1: 3.0 \times 10^{5} \mathrm{CFU} / \mathrm{mL} ; 2: 3.0 \times 10^{4} \mathrm{CFU} / \mathrm{mL} ; 3: 3.0 \times 10^{3} \mathrm{CFU} / \mathrm{mL} ; 4: 3.0 \times 10^{2} \mathrm{CFU} / \mathrm{mL} ; 5: 3.0 \times 10^{1} \mathrm{CFU} / \mathrm{mL}$. (B) Electrophoretic analysis of EHEC O157:H7 polymerase chain reaction (PCR)-amplified products. M: 2000bp marker; 1: Negative control; 2: 3.0 $\times 10^{5} \mathrm{CFU} /$ $\mathrm{mL} ; 3: 3.0 \times 10^{4} \mathrm{CFU} / \mathrm{mL}$ 4: $3.0 \times 10^{3} \mathrm{CFU} / \mathrm{mL} ; 5: 3.0 \times 10^{2} \mathrm{CFU} / \mathrm{mL} ; 6: 3.0 \times 10^{1} \mathrm{CFU} / \mathrm{mL}$. PCR amplification bands could be detected in agarose gel electrophoresis only up to a final dilution of $3.0 \times 10^{2} \mathrm{CFU} / \mathrm{mL}$. The sensitivity of IMS-LAMP assay was 10 times more than the PCR.

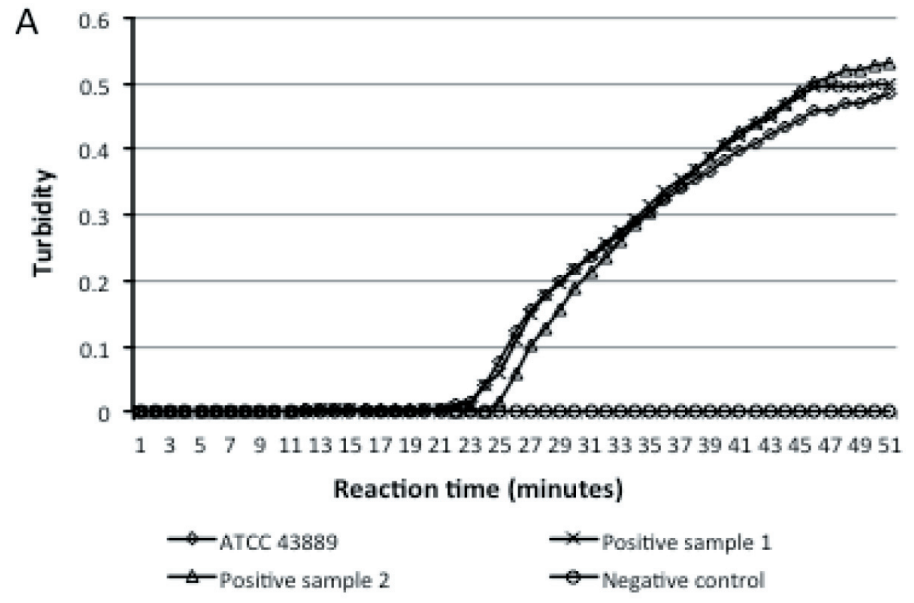

B

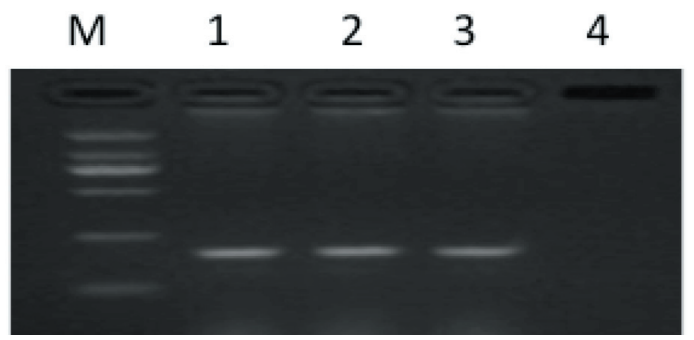

FIGURE 6. Evaluation of IMS-LAMP assay and IMS-PCR method for EHEC O157:H7 in practice. (A) IMS-LAMP assay of two positive samples of EHEC O157:H7 with one positive control (EHEC O157: H7 ATCC 43889) from 39 meat samples analyzed. The three corresponding curves of genomic DNA corresponds to one positive control (EHEC O157: H7 ATCC 43889) and two positive samples contaminated with EHEC O157:H7. (B) Electrophoretic analysis of IMS-PCR products. Lane M: 2000bp marker; Lane 1: Positive control, EHEC O157: H7 ATCC 43889; Lane 2 \& 3: two positive samples of EHEC O157:H7 and Lane 4: Non-O157 E.coli as negative control.

gen in 1997 [Orskov \& Orskov, 1992]. EHEC O157:H7 is clinically important due to its high virulence, extremely low infectious dose, and its ability to cause serious illness after a short course of acute infection. Identification of food source with traditional detection methods based on isolation by bacterial culture and confirmation with biotyping and serotyping is unreliable, as it is more time consuming and often shows low sensitivity in recovering small numbers from the samples [Chapman et al., 2001]. As an emerging foodborne bacterial pathogen, there is an urgent need to develop simple, rapid, sensitive and specific detection methods to ensure food safety, effective prevention and control of EHEC 0157:H7 spread. 
For EHEC O157:H7 detection, from the food source, three broad categories of assays are currently available. They include, the traditional SMAC plating method [Gould et al., 2009], enzyme immunoassays (EIAs) for Shiga toxins and a few EHEC serogroups [CDC, 2006], and Nucleic Acid Amplification Tests (NAATs) such as PCR and qPCR to detect the virulence factor genes [Fratamico et al., 2011; Mori \& Notomi, 2009; Notomi et al., 2000]. Conventional PCR amplification using a single set of primers, a technically-demanding assay for the detection of EHEC O157:H7, can be a rapid method to detect the presence of the bacteria in trace samples, but have resulted in non-specific bands questioning its specificity and also requires special equipment, complicated operation and lab facilities which are not cost-effective [Zhao et al., 2010]. LAMP, which is a newer molecular technique developed in this century, is designed for six regions of target genes with 4 kinds of specific primers, using a strand displacement DNA polymerase (BstDNA polymerase) in isothermal conditions (about $65^{\circ} \mathrm{C}$ ) [Hara-Kudo et al., 2007 (missing in references); Mori et al., 2001; Nagamine et al., 2001]. LAMP amplification method is rapid, more sensitive and specific, and therefore can be implemented as a screening assay in the food industry as well as in clinical diagnosis [Sen \& Ashbolt, 2011]. Successful identification of pathogens from a large variety of food products and processed samples was reported by LAMP assay applying Bst DNA polymerase which is less sensitive to inhibitors than Taq polymerase used in the conventional PCR [Aydin et al., 2014; Francois et al., 2011; Ravan et al., 2016; Sattabongkot et al., 2014].

LAMP is able to compensate, to some extent, the shortage of traditional detection methods, but susceptible to interference of certain factors in the sample, especially in meat samples. In our study, we combined immunomagnetic separation of pathogen after enrichment and its subsequent detection with the LAMP technique. Since the surface of immunomagnetic beads coated with anti-O157:H7 antibody can specifically capture target bacteria in samples, it could facilitate the removal of other bacteria causing LAMP interference detection. Hence, our method could concentrate enrichment sample with target bacteria and thus increase the amount of available templates to detect the pathogen with a higher sensitivity compared to any other existing method.

Several studies reported identification of EHEC O157:H7 through various approaches to detect the toxin genes like, stxl, stx2, eaeA, rfbE, Z3276, hlyA and serogroupspecific genes $w z x$ and $w z y$ [Sharma \& Dean-Nystrom, 2003; Wani et al., 2007]. Most of these genes are not very unique for the pathogenic serotypes like EHEC O157:H7. We identified that the $r f b E$ gene coding sequences were highly conserved in all EHEC O157:H7 strains and exhibited strain specific gene expression [Desmarchelier et al., 1998; Jiang et al., 2012].

Out of 19 different bacterial strains we checked, only EHEC O157:H7 (1 standard and 4 wild strains) were positive with LAMP assay to make the specificity $100 \%$, which is consistent with the previous reports showing very high specificity of the LAMP assay in detection of EHEC O157:H7 [Fan et al., 2012; Han \& Ge, 2010; Nemoto et al., 2009]. The LAMP sensitivity of $1.8 \times 10^{1} \mathrm{CFU} / \mathrm{mL}$ with the pure bacterial cultures in our experiment was consistent with the previously reported studies [Han \& Ge, 2010]. When compared with PCR assay, the LAMP assay resulted in a higher specificity and was $10 \%$ more sensitive than PCR assay due to eight distinct sequences that were required for recognition in the LAMP assay [Zeng et al., 2014].

A previous study reported that the binding capacity decreased significantly when IMS was performed with ground beef and attributed the reduced binding capacity to the high fat content of beef, which may entrap some beads in the food matrix [Jeníková et al., 2000]. The results of our study showed that IMS followed by LAMP could capture and detect a bacterial concentration as low as $3 \times 10^{1} \mathrm{CFU} / \mathrm{mL}$ from the meat samples. This sensitivity of the IMS-LAMP assay is more close to the sensitivity of the LAMP assay with pure bacterial culture which indicates that the interference in binding capacity due to the high fat content is obviated by combining the IMS after enrichment with LAMP assay. In future, the use of more specific antibodies and better solutions to block the non-specific sites of immunomagnetic beads could further reduce the number of non-specific interactions.

Immunomagnetic enrichment of 39 ground beef samples collected from the market around our study area detected two positive samples contaminated with EHEC O157:H7 with IMS-LAMP assay. On comparative analysis of the IMSLAMP assay results with the National Standard Method (GB/T4789.6-2003) including positive and negative controls, our IMS-LAMP assay was more rapid and showed higher sensitivity and specificity.

The rapid detection of EHEC O157:H7 at a low limiting number is very important to prevent people from being infected through consumption of contaminated beef. In order to meet this purpose, we standardized IMS-LAMP assay with a $4 \mathrm{~h}$ short incubation so that the whole assay would be completed within $6 \mathrm{~h}$. IMS combined with realistic LAMP method is a simple, rapid, highly specific gene amplification technology which does not require expensive equipment and is suitable for basic laboratory and field tests for detecting food contamination. Hence, the IMS in combination with LAMP can improve the EHEC O157:H7 detection rate in a rapid and convenient way and, thereby, could be implemented as a screening method.

\section{CONCLUSION}

To our knowledge, this is the first report that combined IMS with the LAMP assay to target the species-specific $r f b E$ gene for the rapid detection of EHEC O157:H7 from ground beef samples, and this assay could be implemented as a screening assay for the inspection of meat for contamination. This novel method of detection holds great significance in the prevention and control of EHEC O157:H7 infection and provides a new direction of development in the field of food hygiene inspection with broad prospects in future.

\section{ACKNOWLEDGEMENTS}

The research was supported by the National Natural Science Foundation of China (31300762), Guangdong Province Science and Technology Projects (2012B031800132, 
2013B021500012) and Guangzhou Science and Technology Project (2014J4100146).

\section{CONFLICT OF INTERESTS}

Authors declare no conflict of interests.

\section{REFERENCES}

1. Aydin M., Herzig G.P., Jeong K.C., Dunigan S., Shah P., Ahn S., Rapid and sensitive detection of Escherichia coli O157:H7 in milk and ground beef using magnetic bead-based immunoassay coupled with tyramide signal amplification. J. Food Prot., 2014, 77, 100-105.

2. Bapanpally C., Maganty G., Khan S., Kasra A., Morey A., Immunomagnetic separation and visual fluorescence detection of E. coli $\mathrm{O} 157$ using AOAC approved SAS Molecular Tests. J. AOAC Int., 2014, 97, 1073-1077.

3. Bell B.P., Griffin P.M., Lozano P., Christie D.L., Kobayashi J.M., Tarr P.I., Predictors of hemolytic uremic syndrome in children during a large outbreak of Escherichia coli O157:H7 infections. Pediatrics, 1997, 100, E12

4. Bilge S.S., Vary J.C., Jr, Dowell S.F,, Tarr PI., Role of the Escherichia coli $\mathrm{O} 157: \mathrm{H} 7 \mathrm{O}$ side chain in adherence and analysis of an rfb locus. Infect. Immun., 1996, 64, 4795-4801.

5. Buesa J.B., Collado P., López-Andújar P., Abu-Mallouh R., Rodríguez Díaz J., García Díaz A., Molecular epidemiology of calici viruses causing outbreaks and sporadic cases of acute gastroenteritis in Spain. J. Clin. Microbiol., 2002, 40, 2854-2859

6. CDC, Centers for Disease Control and Prevention, Importance of culture confirmation of Shiga toxin-producing Escherichia coli infection as illustrated by outbreaks of gastroenteritis- New York and North Carolina, 2005. MMWR Morb Mortal Wkly Rep., 2006, 55, 1042-1045.

7. Chapman P.A., Ellin M., Ashton R., A comparison of immunomagnetic separation and culture, RevealTM and VIPTM for the detection of E. coli $\mathrm{O} 157$ in enrichment cultures of naturallycontaminated raw beef, lamb and mixed meat products. Lett. Appl. Microbiol., 2001, 32, 171-175.

8. Chase-Topping M., Gally D., Low C., Matthews L., Woolhouse M., Super-shedding and the link between human infection and livestock carriage of Escherichia coli O157. Nat. Rev. Microbiol., 2008, 6, 904-912.

9. Desmarchelier P.M., Bilge S.S., Fegan N., Mills L., Vary J.C.Jr., Tarr P.I., A PCR specific for Escherichia coli $\mathrm{O} 157$ based on the rfb locus encoding O157 lipopolysaccharide. J. Clin. Microbiol., 1998, 36, 1801-1804.

10. Fan H., Long B., Wu X., Bai Y., Development of a Loop-Mediated Isothermal Amplification Assay for sensitive and rapid detection of Cronobacter sakazakii. Foodborne Pathog. Dis., 2012, 9, 1111-1118.

11. Francois P., Tangomo M., Hibbs J., Bonetti E.J., Boehme C.C., Notomi T., Perkins M.D., Schrenzel J., Robustness of a loopmediated isothermal amplification reaction for diagnostic applications. FEMS Immunol. Med. Microbiol., 2011, 62, 41-48.

12. Fratamico P.M., Bagi L.K., Cray W.C. Jr., Narang N., Yan X., Medina M., Liu Y., Detection by multiplex real-time polymerase chain reaction assays and isolation of Shiga toxin-producing Escherichia coli serogroups O26, O45, O103, O111, O121, and O145 in ground beef. Foodborne Pathog. Dis., 2011, 8, 601-607.

13. Gianviti A., Rosmini F., Caprioli A., Corona R., Matteucci MC., Principato F., Luzzi I., Rizzoni G., Haemolytic-uraemic syndrome in childhood: surveillance and case-control studies in Italy. Italian HUS Study Group. Pediatr. Nephrol., 1994, 8, 705-9.

14. Gould L.H., Bopp C., Strockbine N., Atkinson R., Baselski V., Body B., Carey R., Crandall C., Hurd S., Kaplan R., Neill M., Shea S., Somsel P., Tobin-D’Angelo M., Griffin P.M., Gerner-Smidt P., Centers for Disease Control and Prevention (CDC), Recommendations for diagnosis of Shiga toxin-producing Escherichia coli infections by clinical laboratories. MMWR Recommend Rep., 2009, 58, 1-14.

15. Han F., Ge B., Quantitative detection of Vibrio vulnificus in raw oysters by real-time loop-mediated isothermal amplification. Int. J. Food Microbiol., 2010, 142, 60-66.

16. Hara-Kudo Y., Nemoto J., Ohtsuka K., Segawa Y., Takatori K., Kojima T., Ikedo M., Sensitive and rapid detection of Vero toxinproducing Escherichia coli using loop-mediated isothermal amplification. J. Med. Microbiol., 2007, 56, 398-406.

17. Hara-Kudo Y., Konishi N., Ohtsuka K., Hiramatsu R, Tanaka H, Konuma HK, Takatori K., Detection of verotoxigenic Escherichia coli $\mathrm{O} 157$ and $\mathrm{O} 26$ in food by plating methods and LAMP method: A collaborative study. Int. J. Food Microbiol., 2008, 122, 156-161.

18. Hill J., Beriwal S., Chandra I., Paul V.K., Kapil A., Singh T., Wadowsky R.M., Singh V., Goyal A., Jahnukainen T., Johnson J.R., Tarr P.I., Vats A., Loop-mediated isothermal amplification assay for rapid detection of common strains of Escherichia coli. J. Clin. Microbiol., 2008, 46, 2800-2804.

19. Jeníková G., Pazlarová J., Demnerová K., Detection of Salmonella in food samples by the combination of immunomagnetic separation and PCR assay. Int. Microbiol., 2000, 3, 225-229.

20. Jeon S.J., Elzo M., Dilorenzo N., Lamb G.C., Jeong K.C., Evaluation of animal genetic and physiological factors that affect the prevalence of Escherichia coli O157 in cattle. PLoS One, 2013, 8, e55728.

21. Jiang R., Long B., Zeng G., Wang D., Fan H., Wu X., Loop-mediated isothermal amplification for detecting enterohemorrhagic Escherichia coli O157:H7: a comparison with PCR. Nan Fang Yi Ke Da Xue Xue Bao., 2012, 32, 1026-1030.

22. Karch H., Tarr P.I., Bielaszewska M., Enterohaemorrhagic Escherichia coli in human medicine. Int. J. Med. Microbiol., 2005, 295, 405-418.

23. Kou X., Wu Q., Zhang J., Fan H., Development and application of a loop-mediated isothermal amplification assay on rapid and sensitive detection of rotavirus in fecal samples and artificially seeded oysters. Food Contr., 2014, 41, 151-157.

24. Mckee M.L., O'Brien A.D., Investigation of enterohemorrhagic Escherichia coli $\mathrm{O} 157: \mathrm{H} 7$ adherence characteristics and invasion potential reveals a new attachment pattern shared by intestinal E.coli. Infect Immun., 1995, 63, 2070-2074.

25. Mori Y., Nagamine K., Tomita N., Notomi T., Detection of loopmediated isothermal amplification reaction by turbidity derived from magnesium pyrophosphate formation. Biochem. Biophys. Res. Commun., 2001, 289, 150-154.

26. Mori Y., Notomi T., Loop-mediated isothermal amplification (LAMP): a rapid, accurate, and cost-effective diagnostic method for infectious diseases. J. Infect. Chemother., 2009, 15, 62-69. 
27. Nagamine K., Watanage K., Ohtsuka K., Hase T., Notomi T., Loop-mediated isothermal amplification reaction using a nondenatured template. Clin. Chem., 2001, 47, 1742-1743.

28. Nagamine K., Hase T., Notomi T., Accelerated reaction by loopmediated isothermal amplification using loop primers. Mol. Cell. Probes, 2002, 16, 223-229.

29. Nemoto J., Sugawara C., Akahane K., Hashimoto K., Kojima T., Ikedo M., Konuma H., Hara-Kudo Y., Rapid and specific detection of the thermostable direct hemolysin gene in Vibrio parahaemolyticus by loop-mediated isothermal amplification. J. Food Prot., 2009, 72, 748-754.

30. Notomi T., Okayama H., Masubuchi H., Yonekawa T., Watanabe K., Amino N., Hase T., Loop-mediated isothermal amplification of DNA. Nucleic Acids Res., 2000, 28, E63.

31. Onoue Y., Konuma H., Nakagawa H., Hara-Kudo Y., Fujita T., Kumagai S., Collaborative evaluation of detection methods for Escherichia coli O157:H7 from radish sprouts and ground beef. Int. J. Food Microbiol., 1999, 46, 27-36.

32. Orskov F., Orskov I., Escherichia coli serotyping and disease in man and animals. Can. J. Microbiol., 1992, 38, 699-704.

33. Pruimboom-Brees I.M., Morgan T.W., Ackermann M.R., Nystrom E.D., Samuel J.E., Cornick N.A., Moon H.W., Cattle lack vascular receptors for Escherichia coli O157:H7 Shiga toxins. Proc. Natl. Acad. Sci. USA., 2000, 97, 10325-10329.

34. Ravan H.,, Amandadi M., Sanadgol N., A highly specific and sensitive loop-mediated isothermal amplification method for the detection of Escherichia coli O157:H7. Microb. Pathogen., 2016, 91, 161-165.

35. Saito R., Misawa Y., Moriya K., Koike K., Ubukata K., Okamura N., Development and evaluation of a loop-mediated isothermal amplification assay for rapid detection of Mycoplasma pneumonia. J. Med. Microbiol., 2005, 54, 1037-1041.

36. Sattabongkot J., Tsuboi T., Han E.T., Bantuchai S., Buates S., Loop-mediated isothermal amplification assay for rapid diagnosis of malaria infections in an area of endemicity in Thailand. J. Clin. Microbiol., 2014, 52, 1471-1477.

37. Sen K., Ashbolt N.J., Environmental Microbiology: Current Technology and Water Application. 2011, Caister Academic Press, Norfolk, UK, ISBN; 978(1): 904455-70-7.

38. Sharma V.K., Dean-Nystrom E.A., Detection of enterohemorrhagic Escherichia coli $\mathrm{O} 157: \mathrm{H} 7$ by using a multiplex real-time PCR assay for genes encoding intimin and Shiga toxins. Vet. Microbiol., 2003, 93, 247-260.

39. Taguchi T., Arakaki A., Takeyama H., Haraguchi S., Yoshino M., Kaneko M., Detection of Cryptosporidium parvum oocysts using a microfluidic device equipped with the SUS micromesh and FITC. Biotechnol. Bioeng., 2007, 96, 272-280.

40. Wang F., Jiang L., Ge B., Loop-mediated isothermal amplification assays for detecting shiga toxin-producing Escherichia coli in ground beef and human stools. J. Clin. Microbiol., 2012, 50, 91-97.

41. Wang Y., Wang Y., Luo L., Liu D., Luo X., Xu Y., Hu S., Niu L., Xu J., Ye C., Rapid and sensitive detection of Shigella spp. and Salmonella spp. by Multiple Endonuclease Restriction Real-Time Loop-Mediated Isothermal Amplification Technique. Front. Microbiol., 2015, 6, 1400.

42. Wani S.A., Hussain I., Nabi A., Fayaz I., Nishikawa Y., Variants of eae and stx genes of atypical enteropathogenic Escherichia coli and non-O157 Shiga toxin-producing Escherichia coli from calves. Lett. Appl. Microbiol., 2007, 45, 610-615.

43. Wolf S., Williamson W.M., Hewitt J., Rivera-Aban M., Lin S., Ball A., Scholes P., Greening GE., Sensitive multiplex real-time reverse transcription-PCR assay for the detection of human and animal noroviruses in clinical and environmental samples. Appl. Environ. Microbiol., 2007, 73, 5464-5470.

44. Wright D.J., Chapman P.A., Siddons C.A., Immunomagnetic separation as a sensitive method for isolating E. coli $\mathrm{O} 157$ from food samples. Epidemiol. Infect., 1994, 113, 31-39.

45. Xiong Y., Wang P., Lan R., Ye C., Wang H., Ren J., Jing H., Wang Y., Zhou Z., Bai X., Cui Z., Luo X., Zhao A., Wang Y., Zhang S., Sun H., Wang L., Xu J., A novel Escherichia coli O157:H7 clone causing a major hemolytic uremic syndrome outbreak in China. PLoS One, 2012, 7, e36144.

46. Yamazaki W., Ishibashi M., Kawahara R., Inoue K., Development of a loop-mediated isothermal amplification assay for sensitive and rapid detection of Vibrio parahaemolyticus. BMC Microbiol., 2008, 8, 163.

47. Zeng J., Wei H., Zhang L., Liu X., Zhang H., Cheng J., Ma D., Zhang X., Fu P., Liu L., Rapid detection of Vibrio parahaemolyticus in raw oysters using immunomagnetic separation combined with loop-mediated isothermal amplification. Int. J. Food Microbiol., 2014, 174, 123-128.

48. Zhao X., Li Y., Wang L., You L., Xu Z., Li L., He X., Liu Y., Wang J., Yang L., Development and application of a loopmediated isothermal amplification method on rapid detection Escherichia coli $\mathrm{O} 157$ strains from food samples. Mol. Biol. Rep., 2010, 37, 2183-2188.

Submitted: 7 October 2016. Revised: 19 December 2016 and 9 February 2017. Accepted: 21 February 2017. Published on-line: 12 July 2017. 